\title{
Intrarenal reflux and the scarred kidney
}

\author{
G. L. ROLLESTON, T. M. J. MALING, and C. J. HODSON* \\ From the Department of Radiology, Christchurch Hospital and Clinical School, New Zealand
}

\begin{abstract}
Rolleston, G. L., Maling, T. M. J., and Hodson, C. J. (1974). Archives of Disease in Childhood, 49, 531. Intrarenal reflux and the scarred kidney. The incidence and significance of intrarenal reflux (pyelotubular backflow) occurring during micturating cystourethrography has been studied in 386 examinations on patients with vesicoureteric reflux. This phenomenon has not been observed in patients over the age of 4 years.

Renal damage having the radiographic appearance of 'atrophic pyelonephritic scarring' has been shown in 13 out of 20 kidneys showing intrarenal reflux. In 12 out of these 13 kidneys the damage corresponded exactly to those parts of the kidney in which intrarenal reflux had been evident. We suggest that severe degrees of vesicoureteric reflux and intrarenal reflux form the basis of renal scarring peculiar to 'chronic atrophic pyelonephritis'.
\end{abstract}

In recent years a new phenomenon has been recognized radiographically in patients with vesicoureteric reflux. The contrast medium can be shown to flow into the kidney substance during micturating cystography and opacify large segments of renal tissue (Fig. 1), though occasionally only small areas scarcely larger than a single renal lobule are involved. A preliminary account of the incidence and apparent effect of this intrarenal reflux on the kidneys of infants and young children is presented.

\section{Materials and methods}

A total of 386 micturating cystourethrograms in patients known to have vesicoureteric reflux without urinary tract obstruction have been reviewed. Most, but not all, of these patients were investigated radiologically because of urinary infection. Their ages at the time of the micturating cystourethrogram ranged from 3 days to 48 years (Table I).

Before 1967 the diagnosis of urinary infection at Christchurch Hospital was made on the basis of two consecutive midstream specimens showing a bacterial count of $>100,000$ organisms $/ \mathrm{ml}$, but subsequently the technique of direct bladder puncture has been used (Shannon, Sepp, and Rose, 1969) and any growth of bacteria has been regarded as significant.

Technique of micturating cystourethrography. This has been outlined in detail elsewhere (Maling and Rolleston, 1974). The technique varied slightly

Received 26 November 1973.

^Present address: Memorial University of Newfoundland. depending on the age of the patient, but in all cases contrast material was infused into the bladder under low pressure. To ensure maximum radiographic detail of the upper and lower urinary tracts, films were taken with an overcouch tube and a film focus distance of 40 inches.

Classification of vesicoureteric reflux. Vesicoureteric reflux was classified into three grades of severity-slight, moderate, and gross (Rolleston, Shannon, and Utley, 1970). Reflux was regarded as slight when only incomplete filling of the upper urinary tract occurred; moderate when the urinary tract filled completely with slight dilatation, but without ballooning of the calyces; and gross when there was marked dilatation of the upper urinary tract with obvious ballooning of the calyces.

\section{Results}

Reflux of contrast medium into the renal substance was shown in 16 different patients. It was bilateral in 4 patients and this has provided a total of 20 kidneys with intrarenal reflux. Table I shows the incidence of intrarenal reflux in relation to age. It was not observed in patients over the age of 4 years and was present in $6.7 \%$ of examinations below the age of 5 years.

Intrarenal reflux was seen only in conjunction with moderate or severe degrees of vesicoureteric reflux. However, the incidence of the severer grades of vesicoureteric reflux was no higher in infancy and early childhood than in older children and adults to account for intrarenal reflux only being seen below the age of 5 years. Table I also analyses 


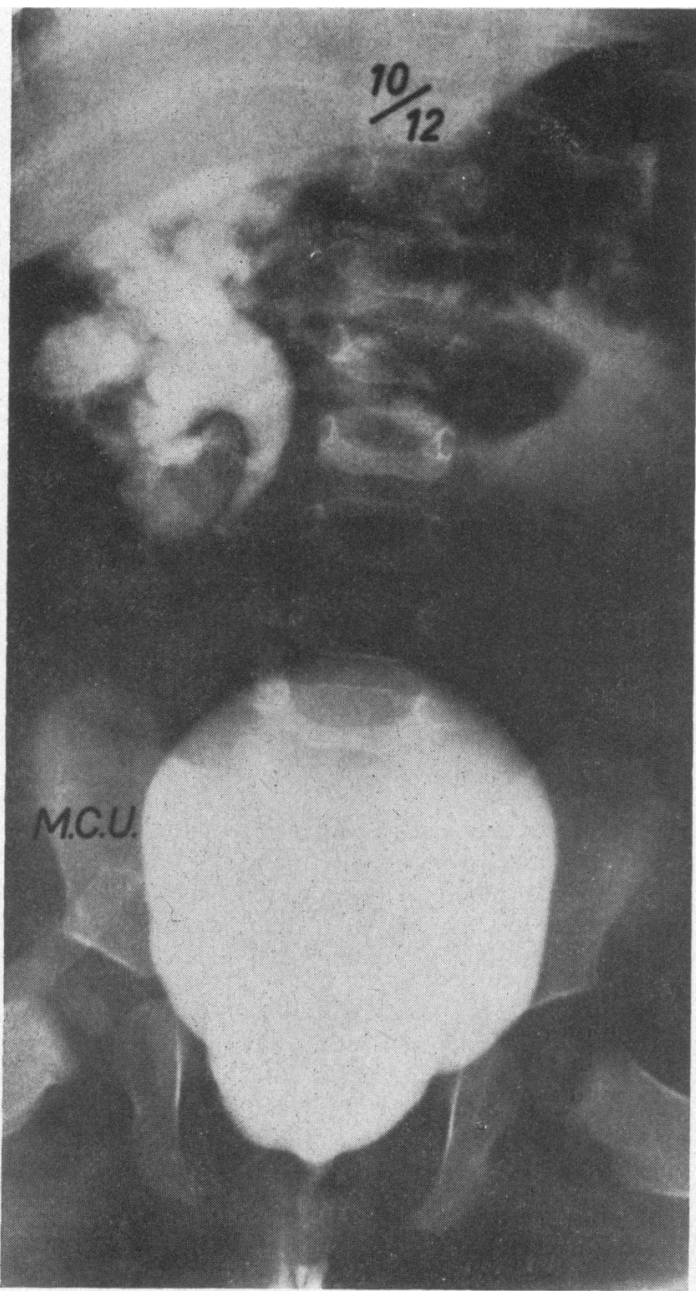

FIG. 1.-Cystogram on a 10-month-old girl showing severe right vesicoureteric reflux with extensive intrarenal reflux involving much of the right kidney. the severity of vesicoureteric reflux found in 564 refluxing ureters during the 386 examinations.

The incidence of renal damage in the 20 kidneys showing intrarenal reflux was assessed on the basis of excretion urography. Renal damage was diagnosed if there was focal loss of kidney substance and papillary damage and/or diminished total renal size. Nine of the 20 kidneys showing intrarenal reflux were damaged at the time of the first examination, and in 8 of these 9 kidneys the damage was directly related to the anatomical area where the intrarenal reflux had been shown. Furthermore, the vesicoureteric reflux had been classified as gross in these 9 kidneys (Table II).

Follow-up examination. 18 of the 20 kidneys which initially showed intrarenal reflux were re-examined by excretion urography at intervals varying from 1 to 10 years to determine whether further damage had occurred. Of these 18 kidneys there were 7 in which damage had been shown at the initial examination. More extensive damage had occurred in 2 of these and was still confined to the same areas (Fig. 2). In the remaining 5 kidneys in which initial damage had been shown, surgical correction of reflux had been performed successfully, and these showed no increase in damage on followup examination (Fig. 3).

Of the other 11 kidneys, which initially were normal, 4 showed evidence of damage at the follow-up examination. In each instance, as in the first group, the damage had occurred in those areas in which intrarenal reflux had been shown at the initial examination (Fig. 4 and 5). Therefore, 13 kidneys out of a total of $20(65 \%)$ in which intrarenal reflux was shown were damaged initially or subsequently (Table II). Furthermore, all 11 kidneys associated with gross vesicoureteric reflux became damaged but only 2 of the 9 associated with moderate reflux were similarly affected (Fig. 5 and 6).

\section{TABLE I}

Incidence of intrarenal reflux and its relation to age, and severity of vesicoureteric reflux related to age

\begin{tabular}{c|c|c|c|c|c|c}
\hline $\begin{array}{c}\text { Age of patients } \\
(\mathrm{yr})\end{array}$ & $\begin{array}{c}\text { Patients with } \\
\text { vesicoureteric reflux }\end{array}$ & $\begin{array}{c}\text { Patients with } \\
\text { intrarenal reflux }\end{array}$ & $\begin{array}{c}\text { Total no. of } \\
\text { refluxing ureters }\end{array}$ & \multicolumn{2}{|c|}{ Degree of vesicoureteric reflux } \\
\hline $0-1$ & 144 & 10 (12 kidneys) & 220 & Slight (\%) & Moderate (\%) & Gross (\%) \\
\hline $1-4$ & 97 & $6(8$ kidneys) & 145 & $23(16)$ & $128(58)$ & $48(22)$ \\
$5-12$ & 103 & 0 & 146 & $53(36)$ & $45(39)$ & $66(45)$ \\
$13+$ & 42 & 0 & $53(33)$ & $17(32)$ & $21(40)$ \\
\hline Total & 386 & 16 & 564 & 135 & 246 & 183 \\
\hline
\end{tabular}


TABLE II

Renal damage and intrarenal reflux and their relation to severity of vesicoureteric reflux

\begin{tabular}{c|c|c|c}
\hline Severity of vesicoureteric reflux & Kidneys with intrarenal reflux & $\begin{array}{c}\text { Kidneys with renal damage at } \\
\text { initial examination }\end{array}$ & $\begin{array}{c}\text { Kidneys with renal damage at } \\
\text { follow-up }\end{array}$ \\
\hline Gross & 11 & 9 & 11 \\
Moderate & 9 & 0 & 2 \\
Slight & 0 & 0 & 0 \\
\hline Total & 20 & 9 & 13 \\
\hline
\end{tabular}

Analysis of renal damage associated with 365 refluxing ureters in children under the age of 5 years disclosed a total of 58 damaged kidneys. Intrarenal reflux was present in $13(24 \%)$ of these kidneys and in 12 the damage corresponded exactly to the area in which intrarenal reflux had been shown.

Voiding cystourethrography. 8 micturating cystourethrograms were performed as part of the follow-up examination of the patients showing intrarenal reflux. In only 1 kidney was there evidence of persisting intrarenal reflux. It was present in the same distribution and degree as before and the interval between the examinations was 18 months (Case 9, Fig. 6). No scarring has occurred yet in this case.
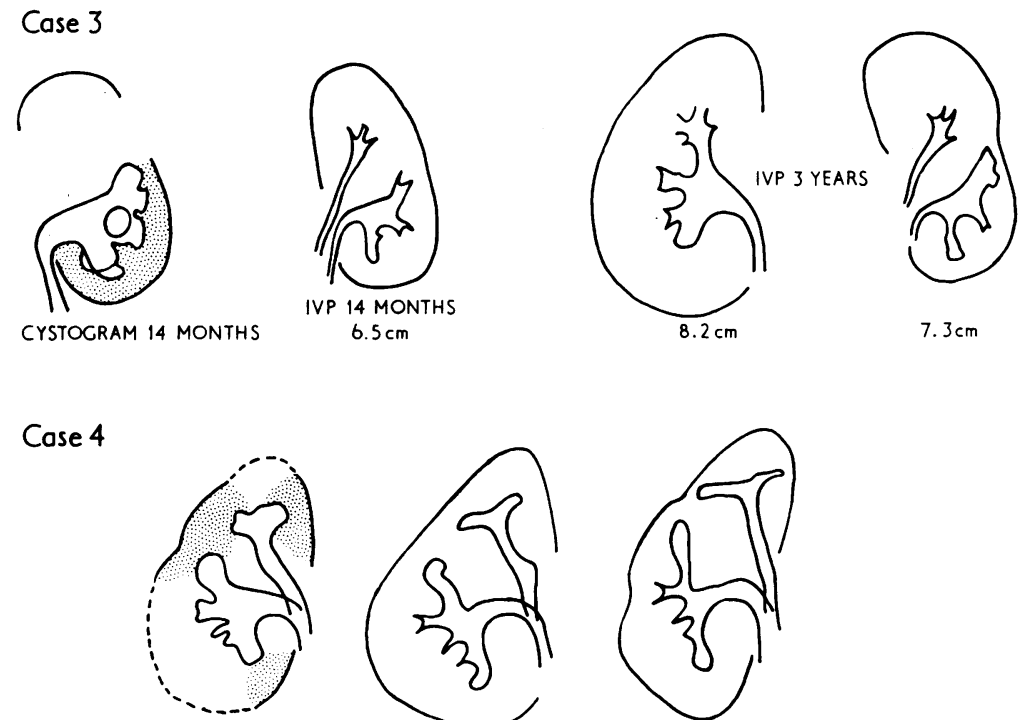

CYSTOGRAM 21 MONTHS
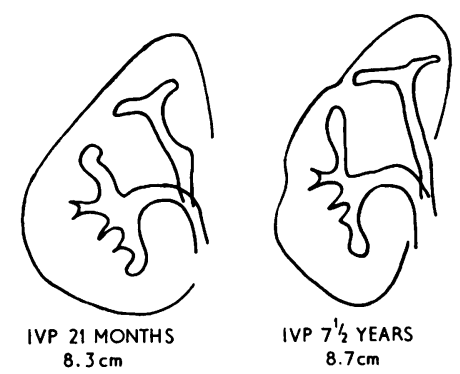

FIG. 2.-Tracings of cystograms and intravenous pyelograms from 2 patients. Both had intrarenal reflux (shaded area) associated with gross vesicoureteric reflux on cystography. At this time intravenous pyelography showed renal damage in the areas corresponding to the intrarenal reflux. At follow-up, the damage was more marked but confined to the same areas. 
Case 5

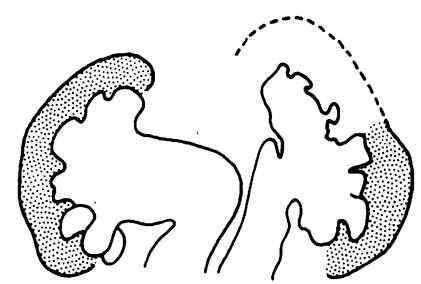

CYSTOGRAM 9 WEEKS

Case 6

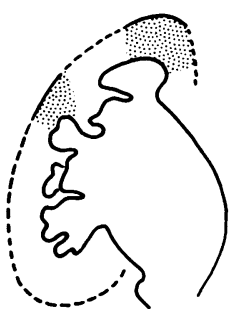

CYSTOGRAM 3 YEARS

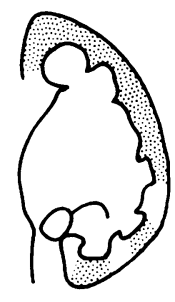

REFLUX SURGICALLY CORRECTED

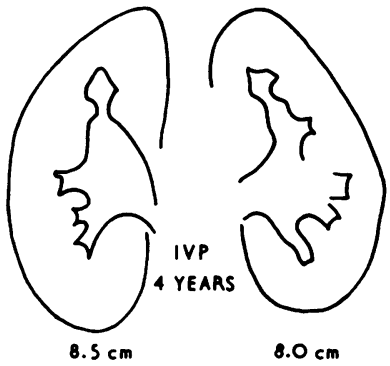

AT 3 YEARS

Cose 7

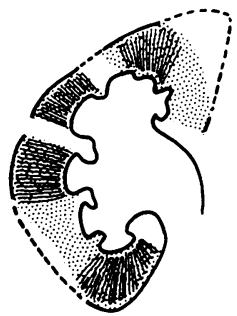

CYSTOCRAM 1O/12 MONTHS

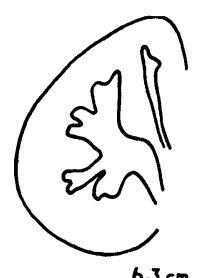

IVP 10/12 MONTHS
SURGICAL CORRECTION OF VUR AT 14 MONTHS

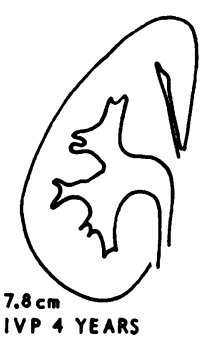

FIG. 3.-Tracings of the cystograms and intravenous pyelograms from Cases 5-7, who all showed intrarenal reflux (shaded areas) associated with gross vesicoureteric reflux at cystography. Renal damage which corresponded to the areas of intrarenal reflux was present at the initial intravenous pyelogram. After surgical correction of the vesicoureteric reflux $(V U R)$ the damage has not progressed and the kidneys have grown.

Amar (1970) reported 8 cases occurring in both children and adults with the oldest patient being 59 years. He called it calicotubular backflow and, in speculating on the role of this phenomenon in chronic pyelonephritis, concluded that this was a route for bacteria 'to initiate, complicate, and perpetuate pyelonephritis'. Mellins (1971) refers to intrarenal reflux as the 'ultimate step' in the process of infection of the renal parenchyma.

It seems certain, both from the work of Brodeur $e t$ al. (1965) and experimental work on animals, that the phenomenon is a form of pyelotubular backflow (the term intrarenal reflux has been used to emphasize its association with vesicoureteric reflux).
Pyelotubular backflow is the least commonly seen of the various forms of breakout from the pelvis and calyces due to an increase in pressure. The other three, i.e. pyelovenous, pyelointerstitial, and pyelolymphatic backflow, are more common and result from a severe acute rise in pressure as occurs when a calculus is impacted in the ureter.

The accumulated clinical evidence suggested that intrarenal reflux could be associated with focal renal damage. This clinical study provides further evidence of this association.

The chief interest of the above observations obviously lies in the 0 to 4 age group where a relation between vesicoureteric reflux, intrarenal reflux, 


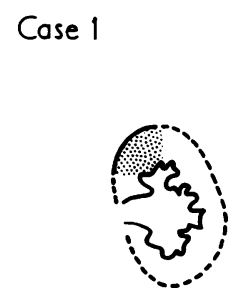

CYSTOCRAM 1 WEEK

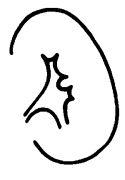

IVP I WEEK

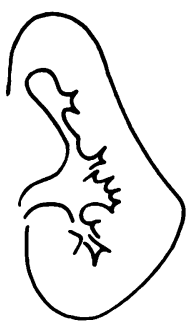

IVP 5 YEARS

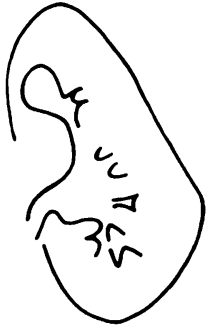

IVP 7 YEARS
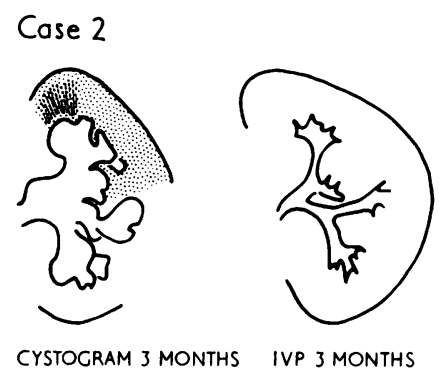

7. $3 \mathrm{~cm}$
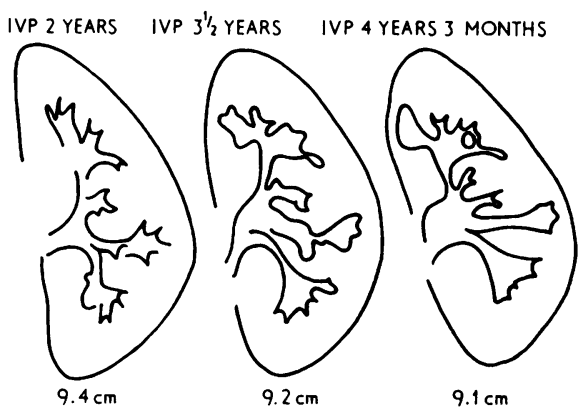

Fig. 4.-Tracings of cystograms and intravenous pyelograms from 2 patients. Both had intrarenal reflux (shaded areas) associated with gross vesicoureteric reflux on cystography, but normal kidneys on intravenous pyelography at this time. Follow-up intravenous pyelography showed the appearance of renal damage in areas corresponding to the intrarenal reflux.

infection, and focal renal damage is so suggestive. These children were investigated simply on the basis of proven bacteriuria, but those with obvious obstructive lesions have been excluded. It must be emphasized also that these data are derived from a retrospective radiological study extending back over 10 years, which was not in all cases orientated towards fine renal definition during micturating cystography. In spite of this, intrarenal reflux was shown in $6.7 \%$ of cystograms in children under the age of 5 with vesicoureteric reflux. It is almost certain that this is an underestimate of its true incidence, as we consider its radiographic demonstration very much depends on the technique used (Maling and Rolleston, 1974).

That intrarenal reflux was not shown over the age of 5 years is impressive and requires explanation. Though it has been shown occasionally in older children and even in adults, this was not the case in this series. It is unlikely that this was due to radiographic technique as the procedure was varied only slightly in the older age groups. It is well recognized that vesicoureteric reflux decreases with age both in frequency and degree (Rolleston et al., 1970), but this again appears to be an insufficient explanation. Some factor appears to be present in these very young children which predisposes to intrarenal reflux.

Of equal interest is the observation that intrarenal reflux was only seen in association with the more severe degrees of vesicoureteric reflux and that the incidence of intrarenal reflux was higher in the gross than in the moderate grades. These findings suggest that not only does its very existence depend on vesicoureteric reflux but that back pressure probably plays some part in its occurrence.

Most striking of all is the data bearing on the association between intrarenal reflux and focal renal damage. This damage is, in the main, radiologically identical to atrophic pyelonephritic scarring. Of the kidneys in which intrarenal reflux was shown, $65 \%$ showed focal renal damage by the end of the follow-up period. This amounts to $24 \%$ of the total number of damaged kidneys in children under the age of 5 years in this series. In 12 out of the 13 kidneys which finally showed focal damage, this corresponded exactly to those parts of the kidney in which intrarenal reflux had been shown. This remarkable observation is good evidence of a pathogenic relation between intrarenal reflux and focal scarring.

Underlying the vast amount of investigation that 
Cose 8
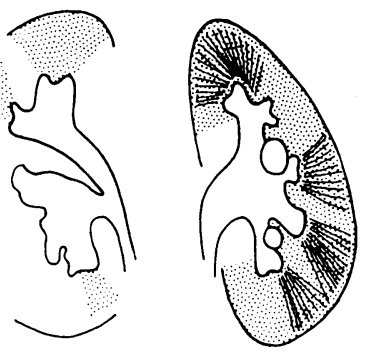

CYSTOCRAM 3 YEARS

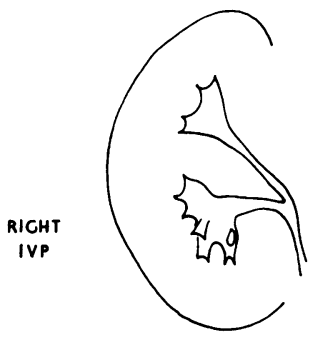

3 YEARS $8.5 \mathrm{~cm}$

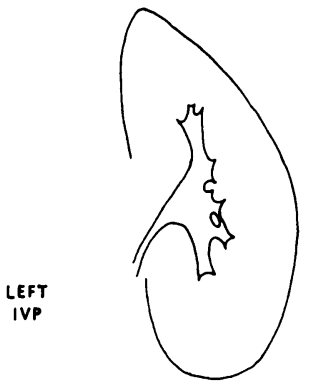

J YEARS $9.5 \mathrm{~cm}$

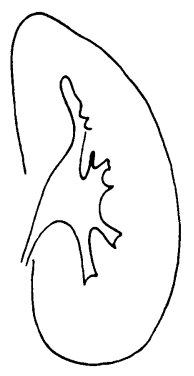

$41 / 2$ YEARS $9.0 \mathrm{~cm}$

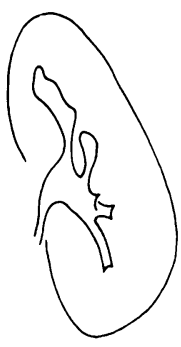

6 YEARS $8.5 \mathrm{~cm}$

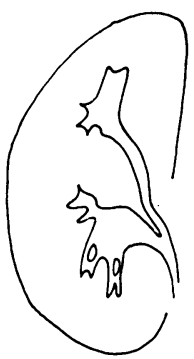

$4^{1 / 2}$ YEARS $9.0 \mathrm{~cm}$

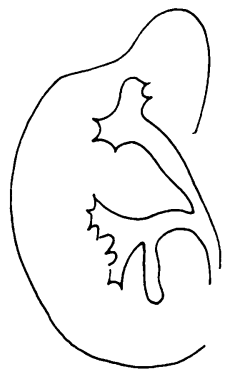

6 YEARS $9.5 \mathrm{~cm}$

FIG. 5.-Tracings of cystogram and serial intravenous pyelograms from a child. There is intrarenal reflux (shaded area) associated with vesicoureteric reflux which was classified as moderate, but with subsequent development of renal damage in areas corresponding to the previously shown intrarenal reflux.

has been carried out in recent years on children with urinary tract infection has been the problem of defining which 'kidney is at risk' so that appropriate treatment can be undertaken to prevent scarring if possible. In the light of these data, no physician can give a reassuring prognostication for any child in which intrarenal reflux and severe vesicoureteric reflux have been shown.

Period of follow-19. a

\begin{tabular}{|c|c|c|c|c|c|}
\hline Case no. & Sex & $\begin{array}{c}\text { Age at } \\
\text { presentation }\end{array}$ & $\begin{array}{c}\text { Period of } \\
\text { follow-up ( } y x)\end{array}$ & $\begin{array}{l}\text { No. of occasions } \\
\text { urine examined }\end{array}$ & 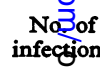 \\
\hline $\begin{array}{l}1 \\
2 \\
3 \\
4 \\
5\end{array}$ & $\begin{array}{l}\mathbf{F} \\
\mathbf{F} \\
\mathbf{F} \\
\mathbf{F} \\
\mathbf{M}\end{array}$ & $\begin{array}{c}10 \mathrm{dy} \\
3 \mathrm{mth} \\
14 \mathrm{mth} \\
21 \mathrm{mth} \\
7 \mathrm{wk}\end{array}$ & $\begin{array}{l}9 \\
5 \\
3 \\
5 \\
5\end{array}$ & $\begin{array}{r}23 \\
37 \\
4 \\
2 \\
53\end{array}$ & $\begin{array}{l}\frac{8}{8} \\
\text { Ni⿱ } \\
\text { Nib } \\
10\end{array}$ \\
\hline 6 & $\mathbf{M}$ & $21 \mathrm{yr}$ & 5 & 17 & N \\
\hline 7 & $\mathbf{F}$ & $10 \mathrm{mth}$ & 3 & 23 & 岁 \\
\hline $\begin{array}{r}8 \\
9 \\
10 \\
11 \\
12 \\
13 \\
14 \\
15 \\
16\end{array}$ & $\begin{array}{l}\mathbf{F} \\
\mathbf{M} \\
\mathbf{F} \\
\mathbf{F} \\
\mathbf{M} \\
\mathbf{M} \\
\mathbf{M} \\
\mathbf{F} \\
\mathbf{M}\end{array}$ & $\begin{array}{l}3 \mathrm{yr} \\
7 \mathrm{wk} \\
7 \mathrm{mth} \\
3 \mathrm{yr} \\
3 \mathrm{wk} \\
2 \mathrm{mth} \\
3 \mathrm{mth} \\
3 \mathrm{yr} \\
4 \mathrm{wk}\end{array}$ & $\begin{array}{c}3 \\
2 \\
10 \\
1 \\
6 \\
3 \\
2 \\
\text { Nil } \\
\text { Died-septicaemia }\end{array}$ & $\begin{array}{r}22 \\
17 \\
7 \\
6 \\
14 \\
13 \\
8\end{array}$ & 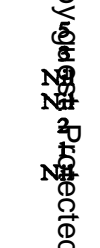 \\
\hline
\end{tabular}


Case 9
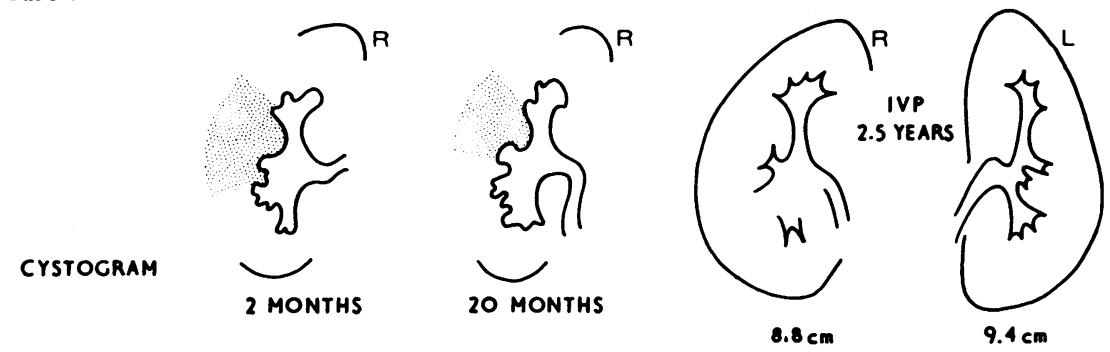

Case 10
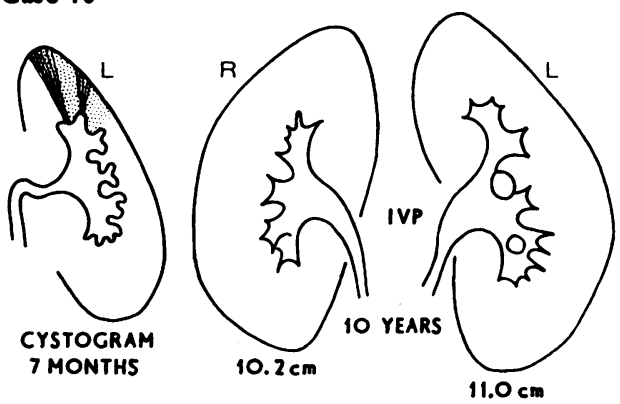

Case II

Case 13

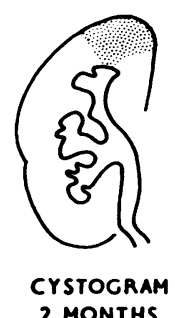

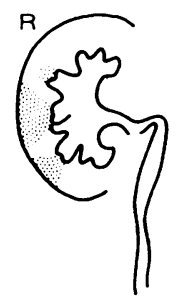
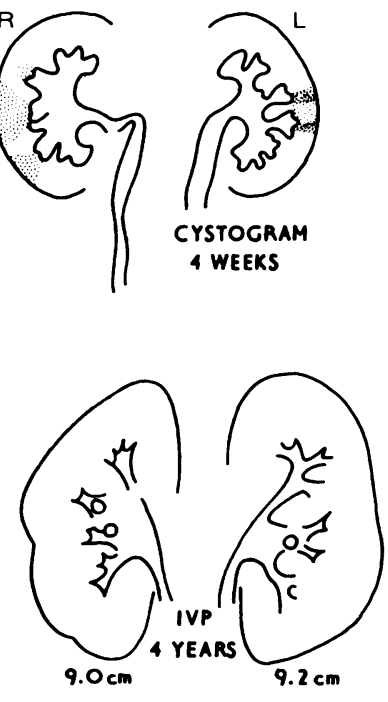
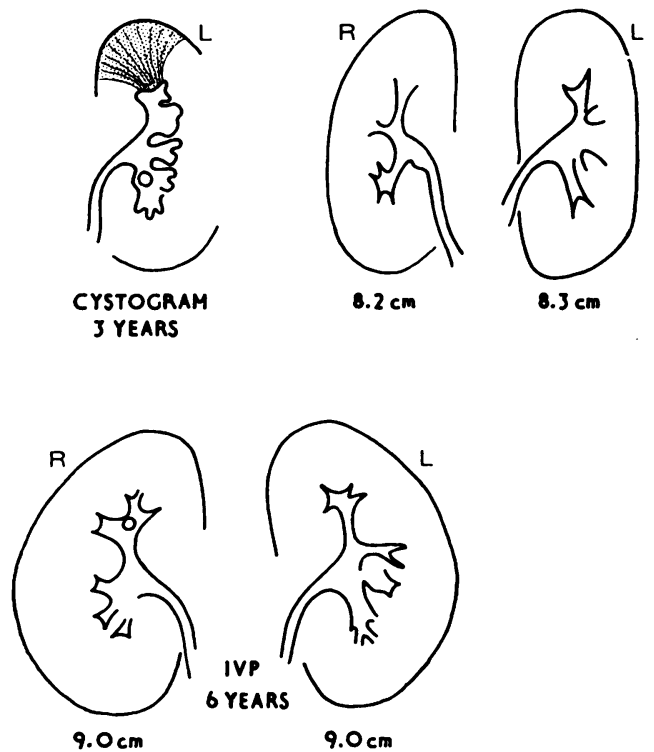

Case 14
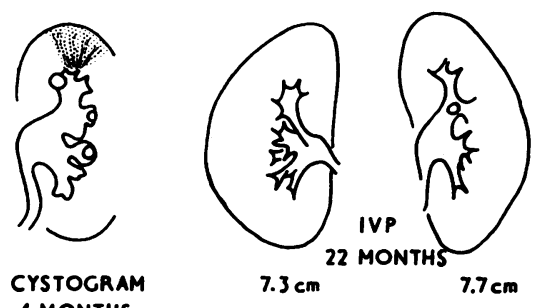

4 MONTHS

FIG. 6.-Tracings of cystograms and intravenous pyelograms from 6 patients show intrarenal reflux (shaded areas) associated with moderate vesicoureteric reflux at cystography. Follow-up intravenous pyelograms show kidneys without damage and with normal growth.

occasion on routine follow-up was bacteriuria detected (Table III). These include some patients whose kidneys remained normal and others in whom scars progressed.
In 3 of the patients who had moderate vesicoureteric reflux with intrarenal reflux the kidneys have continued to grow normally despite proven episodes of bacteriuria in the follow-up period 
(Table III). Many questions concerning the relation of urinary infection and renal scarring have no answer at present and the whole subject demands close study. (An account of extensive experimental work supporting most of the ideas in this article is in preparation for publication, indicating, among other things, that intrarenal reflux is indeed pyelotubular backflow and that focal scarring can occur in the experimental animal in a sterile situation.)

We are indebted to the paediatricians, urologists, and renal physicians at Christchurch Hospital who have referred patients for investigation and have contributed to our understanding of vesicoureteric reflux by frank and free discussion.

In particular we wish to acknowledge the helpful advice, collaboration, and follow-up clinical data provided by Professor F. T. Shannon and Mr. W. L. F. Utley.
REFERENCES

Amar, A. D. (1970). Calicotubular backflow with vesicoureteral reflux. Fournal of the American Medical Association, 213, 293.

Brodeur, A. E., Goyer, R. A., and Melick, W. (1965). A potential hazard of barium cystography. Radiology, 85, 1080.

Hodson, C. J. (1969). The effects of disturbance of flow on the kidney. Fournal of Infectious Diseases, 120, 54.

Hodson, C. J., and Craven, J. D. (1966). The radiology of obstructive atrophy of the kidney. Clinical Radiology, 17, 305.

Maling, T. M. J., and Rolleston, G. L. (1974). Intra-renal reflux in children demonstrated by micturating cystography. Clinical Radiology, 25, 81.

Mellins, H. Z. (1971). Chronic pyelonephritis and renal medullary necrosis. Seminars in Roentgenology, 6, 292.

Rolleston, G. L., Shannon, F. T., and Utley, W. L. F. (1970) Relationship of infantile vesico-ureteric reflux to renal damage. British Medical fournal, 1, 460.

Shannon, F. T., Sepp, E., and Rose, G. R. (1969). Diagnosis of bacteriuria by bladder puncture in infancy and childhood. Australian Paediatric fournal, 5, 97.

Correspondence to Dr. T. M. J. Maling, Department of Radiology, Christchurch Hospital, Christchurch 1, New Zealand. 